\title{
Morphological Transformation of the Wanchai District of Hong Kong
}

\author{
Ling Xiaohong ${ }^{1, a^{*}}$ \\ ${ }^{1}$ School of Architecture, South China University of Technology, Tianhe District, Guangzhou, China \\ aarlingxh@scut.edu.cn
}

Keywords: Morphological transformation, Wanchai of Hong Kong, space syntax

Abstract: Analyzing morphological transformation over a long history of time is deemed an effective way to identify the problems occurred in the process of urban development, in addition to achieving a fundamental understating of the socio-cultural changes and growth rooted from the context. Whilst numerous redevelopment projects of Hong Kong were criticized to ignore and destroy the old urban fabric, this study then provides a morphological analysis of urban evolution based on the Wanchai District, which particularly epitomizes various urban grids that may have different implications for social aspects. Through analyzing its spatial and functional transformation over the past 170 years, this study reveals certain spatial logic underlying different grid patterns and their ever-changing relationship. It is hoped that the findings can provide reference for future spatial development in other similar urban environment of Hong Kong.

\section{Introduction}

a complex artifact, urban morphology not only represents the past but also conceals potentials for the growth of a city in the future[1]. Hence, analyzing the morphological transformation over a historical period of time can help identify the problems occurred in the process of urban development, in addition to achieving a fundamental understating of the socio-cultural changes and growth rooted from the context. As far as urban morphology is concerned, Hong Kong is characterized by its unique high density and compact pattern, which has aroused the interest of a number of authors in the urban design domain. However, such a compact urban morphology does not occur by chance, but by the dedication of a number of physical and socio-economic factors [2].

Urban development of Hong Kong can be traced back to 1841, when Hong Kong Island was ceded to the British. Initial settlement mainly took place in the northern part of the island, followed by expansion along the waterfront upwards to the foothills of Victoria Peak. With the ceding of the Kowloon Peninsula to the British Government in 1861, urban development was spurred on in Kowloon, resulting in spatial development mainly along the costal strips around the inner harbor area (Fig. 1a). In the main, the urban area as a whole was not planned by nature, but rather developed spontaneously through a progressive process of land reclamation. Owing to such a bit-by-bit development, urban fabric of Hong Kong has displayed a seemingly fragmented and complicated pattern, where street grids were laid out on different reclaimed land, and each of them has developed its own character over a long history of time.

Nowadays, the urban area of Hong Kong is still undergoing the process of development and redevelopment. Whilst an increasing number of redevelopment projects were criticized to have ignored or destroyed the structure of old urban fabric, there is a need for research to answer the questions as to what is essence of the exiting urban morphology and how it has been transformed over the past two centuries or so. It is widely believed that without a precise understanding of these questions, it is unlikely to implement an appropriate spatial development in the future. In light of the research purpose as set, this study then chooses the Wanchai District of Hong Kong, which particularly epitomizes various urban grids of Hong Kong, as a case study area. Through providing a morphological analysis 
from the perspective of space syntax, a syntactic and topological approach, it is hoped that the understanding can provide reference for carrying out further spatial development in the other urban areas of Hong Kong.

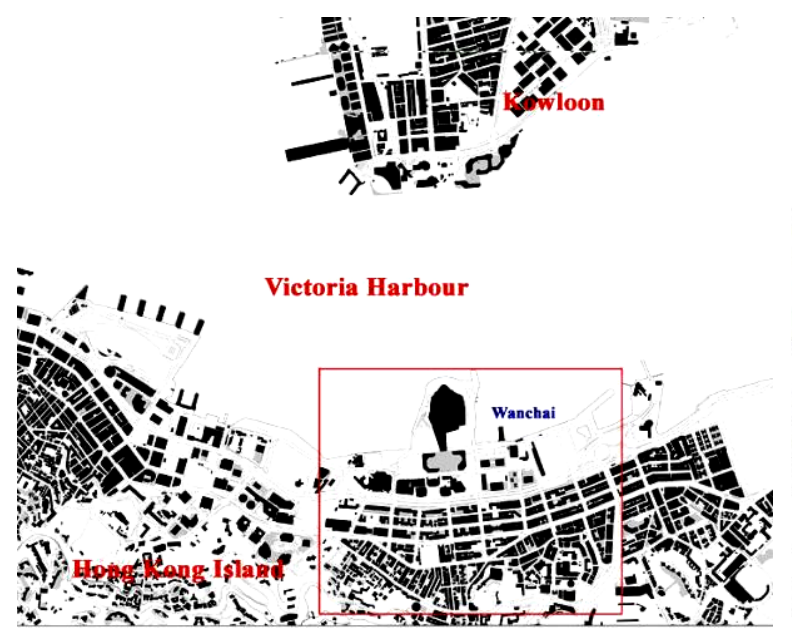

(a)Main urban areas of Hong Kong

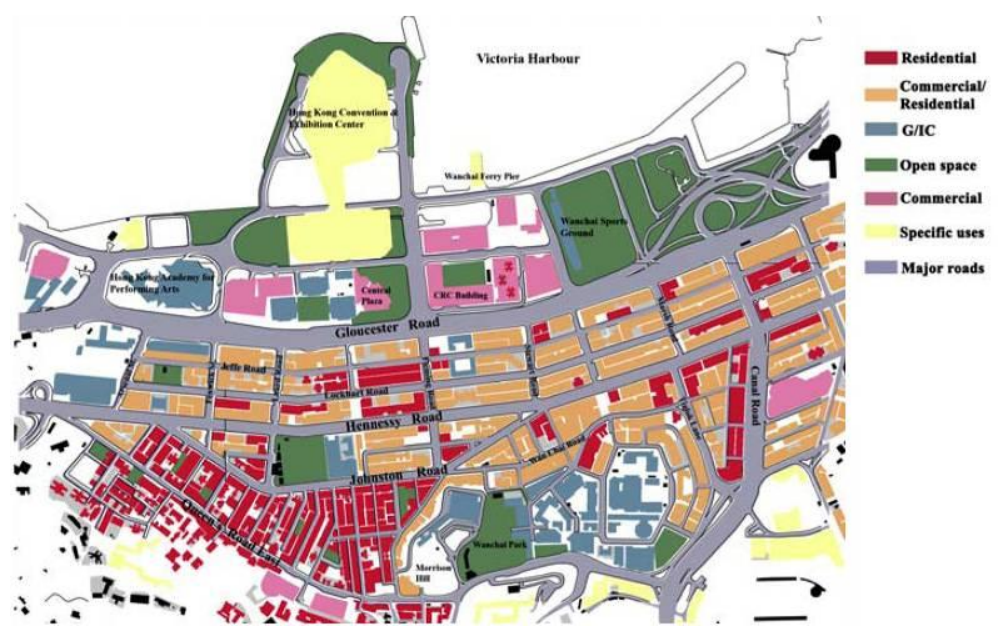

(b) Land use pattern of wanchai

Fig. 1: Urban comple xity of Hong Kong

\section{Lite rature review: space syntax and its analytical techniques}

Space syntax is the theory and a set of techniques to cope with spatial and functional complexity of built environment [3]. Being developed by Professor Bill Hillier and his colleague at Bartlett School of UCL since the 1980s, space syntax answers the question of whether there exist the generic spatial laws mediating pattern of space use and movement and further having social consequences $[3,4,5,6,7,8]$. In light of space syntax, city is a complex entity. With few exceptions, cities normally came into existence through a continuous process of growth and changes over a long history so that they display both spatial and functional complexity[4]. To capture the complexity, there is a need to investigate the urban morphology by understanding the urban system comprehensively as "a spatial and functional whole" [4].

In comparison with other urban morphology studies focusing on form and properties of building s or other constituent elements of the physical environment, space syntax views the relational pattern, that is, the configuration of urban space system arranged by buildings as the crucial element, because it is the key to the form of cities and to how the cities are used and experienced [4]. The configuration concepts stems from the thinking of the formation of built environments, which can be defined as the relation between two spaces taking into account of a third or all the other spaces in a complex system. Hillier [4] indicates that in terms of spatial or formal organization, built environments are configurational entities, whose form is not given by natural laws. Instead, built environment as the largest and most complex artifact, is an organized system. Its primary nature is configurational, principally because it is through spatial configuration that the social purposes for which the built environment is created are expressed [4]. Since space syntax was developed, it has been employed in various contexts, and has been proven that spatial configuration could act as the independent entity to impact on movement patterns, social interacts and land uses choices, both locally and globally $[9,10]$.

In space syntax, the configuration analysis starts with the representational techniques: 'convex spaces', defined by polygons where no line drawn between any two points in the space goes outside it; 'axial lines', defined as the longest and fewest straight lines of visibility and permeability that cover all 
the convex spaces, represent the one-dimensional organization of the spatial layout [4]. The axial-line map is an important representation of the configuration of urban street networks in space syntax, where warmer color or darker axial lines have high global or local integration value, vice versa. To quantify the properties of configuration, depth as a basic unit is introduced into space syntax to measure the necessary steps from a given axial line that are needed to go through to another given axial line.

Based on the concept of depth, a number of syntactic variables are developed to describe the configurational properties of a plan layout. Among these variables, connectivity measures the degree of intersection or one step possibilities of each axial line. Global integration $(\mathrm{Rn})$ is a description of the level of ease or difficulty in getting to a certain line from all other lines in the system, it thereby reflects the 'relative accessibility' of certain space within the urban system as a whole. Contrastingly, Local integration (R3) is another measurement, which considers three steps from the space itself, and is also called radius-3 integration in comparison with global integration ( $\mathrm{Rn})$. In addition, a number of extended syntactic variables are also developed. Integration core (Syntactic core), is the one helping understand syntactic centrality and major order of integration in spatial configuration [11]. Conventionally, integration core comprises 5\% - 25\% of the most integrated lines of all axial lines according to the highest integration rank. In syntactic sense, integration core represents the most accessible place within a system. Hence, by examining the core features, it allows research to identify the distribution pattern of relative accessibility of the system. Intelligibility is another important variable, which is defined as the degree to which what can be seen and experienced locally in the system allows the large scale system to be learnt without conscious effort [4]. The intelligibility value is calculated by the degree of linear correlation between connectivity and global integration value [3]. Under some circumstances, synergy rather than intelligibility, which is calculated by the degree of linear correlation between local and global integration values, is used to lessen the influence of system size [12].

\section{Physical analysis of urban morphology of Wanchai}

\section{A brief historical review}

Wanchai is one of the oldest districts on Hong Kong Island. It is situated between Central and Causeway Bay, with Victoria Harbor to its north and the mountain to its south. The total area of Wanchai is about 134.15 hectares, and accommodates 167,1461 residents ${ }^{1}$. It is estimated that in the coming five years, the total population will not change dramatically, but will show a slight growth in the number of people over 65.

The initial development of the metro urban area of Hong Kong began from Wanchai and Central. Over the past two centuries or so, Wanchai has gone through rapid urban growth and incremental changes, which have characterized it as a unique area, mixing old and new, and mixing local inhabitants and tourists at the same time. Unlike Central, Wanchai in the past was mainly a residential district. After the construction of the Mass Transit Railway in 1975, a large number of luxury commercial and office buildings began to emerge within the area. Gradually, it has transformed from a mainly residential area into a mixed-use district (Fig. 1b, Table-1). However, its mixed land use is not limited to particular sites, but is distributed across the whole district. Resulting from different stages of land reclamation carried out by the government, the urban fabric of Wanchai has displayed a 'segmentline'2 pattern, where different characteristic urban structures are stratified chronologically from the hillside to the harbor. Several main streets, namely: Johnston Road, Hennessy Road and Gloucester Road that used to form the coastline have now become the boundaries between different layout patterns. 


\section{Reclamation as urban development}

As mentioned, the urban layout of Wanchai was not the consequence of a systematic planning, but was developed through a piecemeal reclamation process (Fig. 2). Historically, owing to the constraints of natural settings, Hong Kong Island had very little flat land, and the original settlement was mainly located along the north of the island, the area between Queen's Road and Johnston Road. The development during this period was inclined to be in a relatively small scale, with a block size of 2000$3000 \mathrm{~m}^{2}$ on average, thus can be defined as "Traditional grid" in this study (Fig. 3a, 3b). The overall environment is quite pedestrian friendly, where the streets are about $6-12 \mathrm{~m}$ in width and are arranged in parallel, running from the south to the north towards the harbor. In addition, the street network density is about 0.027, implying that the grid has offered a comparatively higher degree of permeability in comparison with other grid patterns.

Table-1: Surface properties of different grids

\begin{tabular}{|c|c|c|c|}
\hline Surface Properties & "Traditional grid" & "Planne d Grid" & "Sparse Grid" \\
\hline $\operatorname{Areas}\left(\mathbf{M}^{2}\right)$ & 101605.5 & 380394.4 & 301525.0 \\
\hline Local population density(pe rson/hectare) & $\begin{array}{l}\text { Residential mixed } \\
\text { with small-scale } \\
\text { commercial } \\
1600\end{array}$ & $\begin{array}{c}\text { Mixed use } \\
\text { (residential/commercial } \\
\text { official/hotel etc. } \\
920\end{array}$ & $\begin{array}{c}\text { Commercial and } \\
\text { official mixed with } \\
\text { few residential } \\
65.1\end{array}$ \\
\hline Building cove rage & $50 \%$ & $43.8 \%$ & $36.7 \%$ \\
\hline Block size on a ve rage $(\mathrm{M} 2)$ & $2000-3000$ & $3000-5000$ & $4000-6000$ \\
\hline Street width $(M)$ & $6-12$ & $12-24$ & 24-36 \\
\hline Street network density(M/M2) & 0.027 & 0.018 & 0.012 \\
\hline
\end{tabular}

Fig. 2: Different reclamation stages in Wanchai
Source: E. Dalby. Hong Kong Passenger
Transport Study, 1941-1966. 1967)




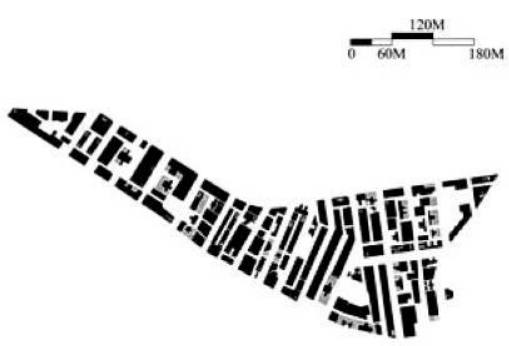

(a) Layout of Wanchai in 1887

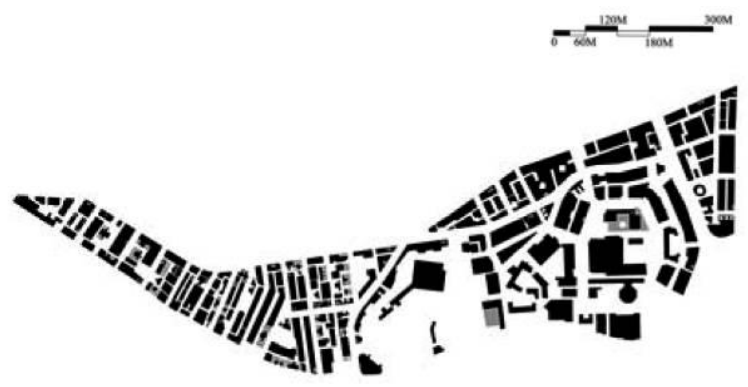

(c) Layout of Wanchai in the early $20^{\text {th }}$ century

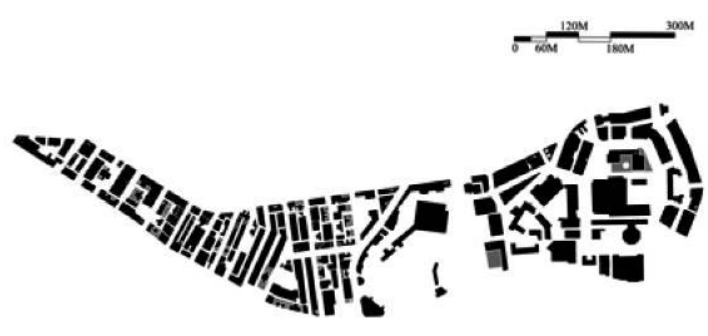

(b) Layout of Wanchai in 1904

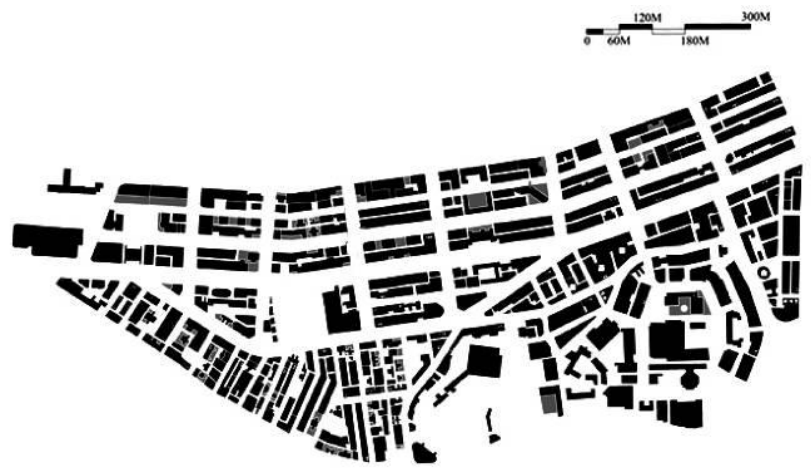

(d) Layout of Wanchai in the 1950s

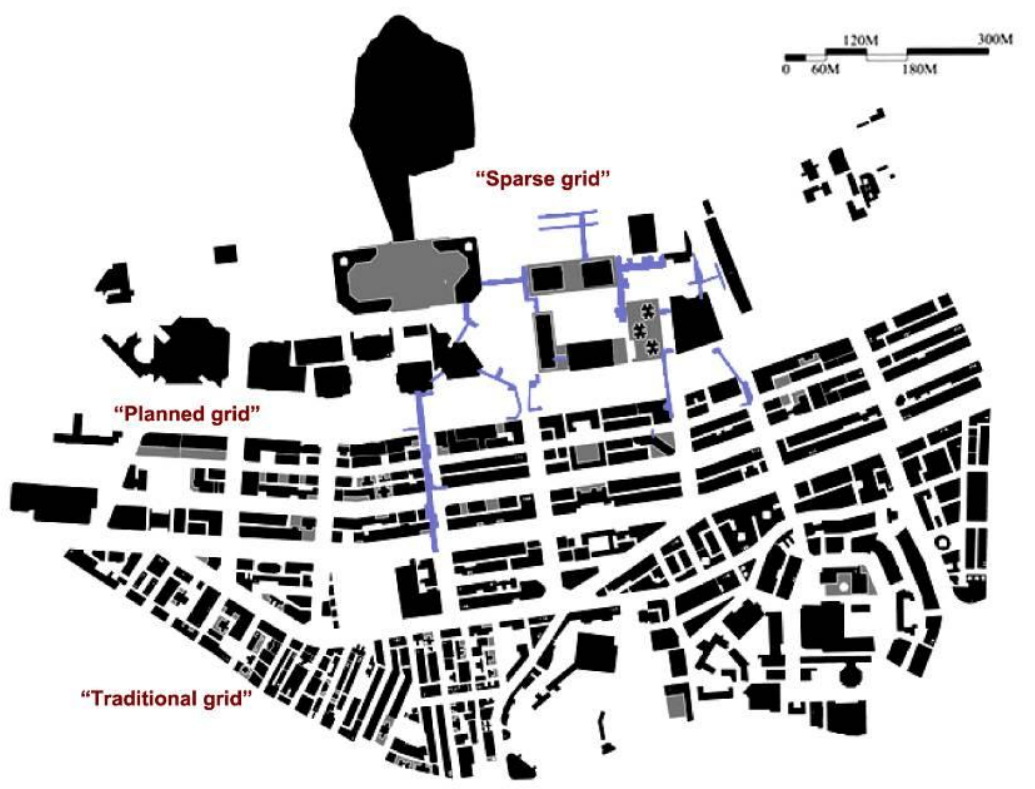

(e) Layout of Wanchai in the 1990s

Fig. 3: Historical Evolution of urban layout of Wanchai

With the development of the shipping industry of Hong Kong, the ever-increasing population, which mainly emigrated from the Mainland, generated a severe land demand inside the settlement. To alleviate the pressure, the Colonial Government began to carry out the first reclamation scheme from the early 20th century. As a result, Johnston Road was added and the development of this parcel of land mainly took the form of three to four storey tenement blocks facing narrow streets. Incidentally, there were almost no community facilities provided. However, the present Southorn Playground, as a civic place accommodating a variety of public activities, was an icon inside the community. Further reclamation was carried out by the Government from 1921 to 1931(Fig. 3c, 3d). The project was known as the Praya East Reclamation Scheme, which has resulted in the provision of 19 acres of land between 
the present Hennessy Road and Gloucester Road. In this area, a grid pattern was laid out and clearly demonstrated a planned nature, thus can be defined as "Planned grid" in this study.

Initially, this area was planned to be developed into a low-rise residential area, along with large lots of open spaces serving the residential population. However, the situation has changed since the early 1970s, when a lot of office and commercial buildings emerged into the district. To maximize the land profit, this area tended to be intensively developed, with few open spaces and other facilities being provided for the residents. In comparison with "Traditional grid", the block size of "Planned grid" is larger, at about $3000-5000 \mathrm{~m}^{2}$ on average. In "Planned grid", the street network density is 0.018 , lower than "Traditional grid", implying that the permeability offered by the network is lower. Street blocks in this area are arranged in a regular grid pattern, facing the streets running from the west to the east. As in "Traditional grid", there is no set-back from the edge of the streets. Instead, buildings fully occupy the blocks, generating a continuous streetscape.

The third large scale reclamation was carried out during the 1980s (Fig. 3e). The newly reclaimed area is now the location of the Hong Kong Convention Exhibition Center (HKCEC). This area was dominated by the first class high-rise buildings. This development was supported by a substantial increase in commercial and office land use, along with a corresponding decrease in residential land use. Although a gridiron street network was still laid out, the street blocks became larger, and the spaces between buildings were sparse and not as well defined as traditionally, thus it can be defined as "Sparse grid". In comparison with other grid patterns to its south, the block size of this area is as large as 5000$6000 \mathrm{~m}^{2}$. Most blocks have setbacks from the edge of the streets, leaving a large amount of open spaces between buildings. In this area, the street network density is fairly low in comparison with the other two grid patterns, with the value of $0.012 \mathrm{~m}$, suggesting that the permeability of the network is comparatively low. In addition, the street network in "Sparse grid" tended to be vehicular oriented, with a net street width between $24 \mathrm{~m}$ and $36 \mathrm{~m}$. Furthermore, apart from the regular street network on the ground level, a second-level pedestrian skywalk system has been built, connecting a number of office and commercial buildings. Notwithstanding the fact that this modern structure was introduced from the western world, it has acquired a different significance in Hong Kong. In truth, the initial function of the skywalk system was to separate pedestrians from vehicles, in addition to providing a climatic-free environment for pedestrians; however, in the Wanchai District and even throughout Hong Kong, it functions as a device, doubling the pedestrian movement density conventionally occurring on the street level. While some other modern cities are suffering from the deserted street life partly owing to the creation of elevated pedestrian networks, the pedestrian activities on the ground level of Wanchai have not been compromised.

View as a whole, through incremental changes and continuous evolution, the urban morphology of Wanchai has exhibited a unique layout pattern, where different spatial layouts were juxtaposed over the past 170 years without the control of a pre-conceived master plan. Therefore, how these varying layout patterns work together as a whole is a question that needs to be clarified in urban morphology studies. In our own time, Wanchai is still in the process of development and redevelopment. The continuous process suggests that there is a need for research to understand the consequent urban configuration and its likely implications for spatial uses.

\section{The evolution of urban configuration}

The historical review of the urban development of Wanchai has illsutrated that the urban morphology has evolved and changed owing to the imperatives of a number of social and economic considerations, for example, the need to accommodate an ever-increasing population and to increase the amount of land for economic development through land reclamation. However, it is unclear 
whether the incremental growth and changes have followed certain spatial or functional logic. The physical analysis in previous sections has provided useful information in this regard, but it only captures the surface characteristics of the grids rather than the deep structure underlying various grid patterns. Hence, in order to investigate whether the progressive urban development has also brought any changes to the configuration of the overall spatial layout, a configuration analysis is carried out. That is, through analyzing a series of axial maps representing the spatial structure in different historical periods, this study attempts to trace the evolution and changes of the configuration of the district. As described, the urban fabric of Wanchai is the consequence of continuous land reclamations, the selection of maps is thereby based on the major reclamation projects of different stages. As a result, four maps from 1842 to the 1990s are selected (Fig. 3). Since global integration (Rn) is always the most significant predictor for functional aspects, including the distribution of pedestrian movement in light of space syntax theory [13], the analysis of this section focuses on syntactic core( $\mathrm{Rn}$ core), global integration $(\mathrm{Rn})$ and its correlation with local integration (R3), that is synergy.

Consequently, Fig. 4a representing the original settlement of Wanchai illustrates that the axial lines along Queen's Road and Johnston Road were the most integrated lines in the settlement, implying that the community activities at that time tended to concentrate along the coastline area and near the hillside. As people began to spread their houses along the hillside to the east, the most integrated lines began to move from Queen's Road to Johnston Road East, rather close to the geometrical center of the settlement (Fig.4b). Also can be seen from the figure, the line representing Johnston Road was well connected with other parts of the system, implying that theoretically it used to be the most accessible and used space within the area. Contrastingly, owing to the peripheral location of Queen's Road, its role as a community center was compromised by the development northwards. 

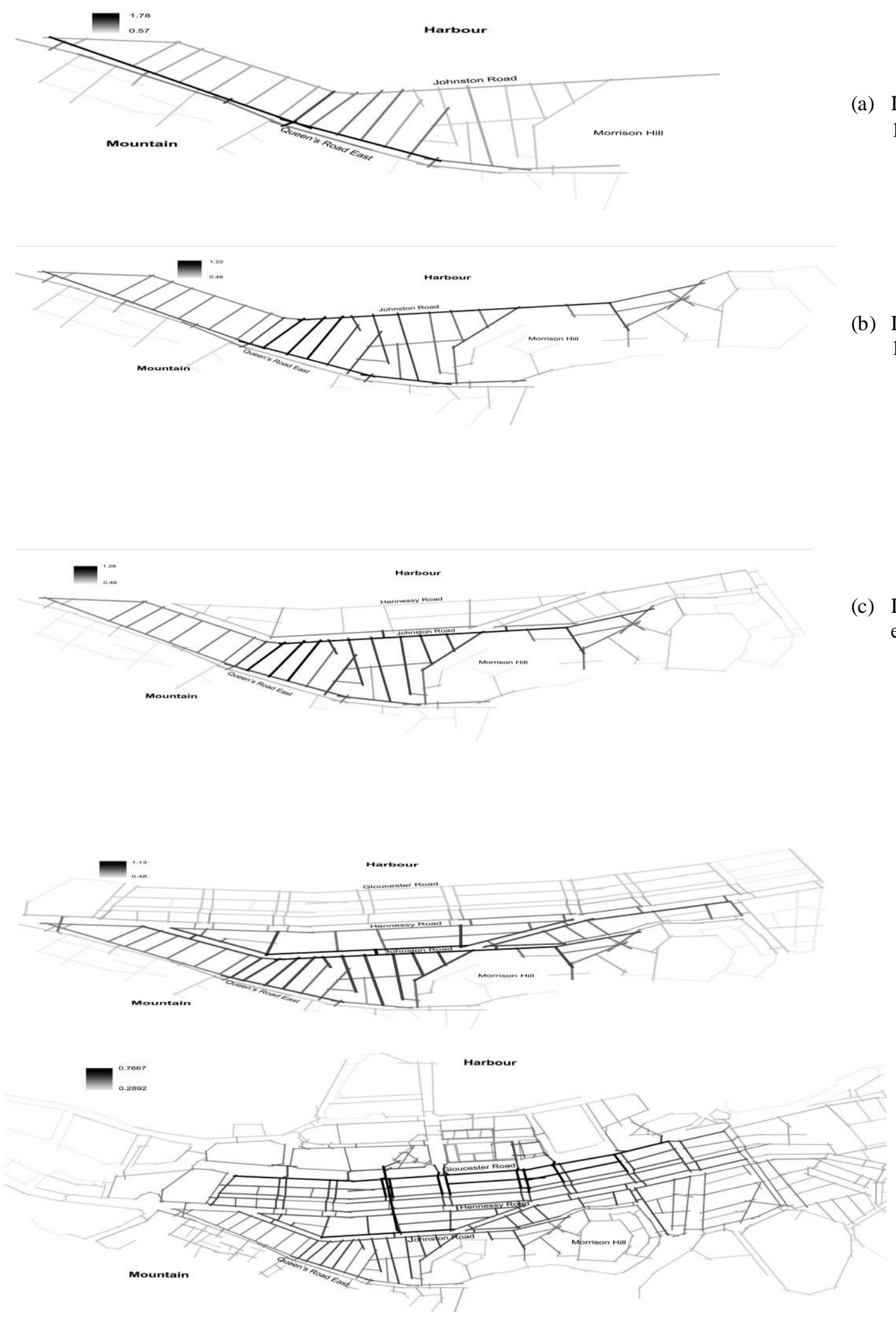

Fig. 4: Evolution of urban configuration of Wanchai (a) Integration map of 1887

(b) Integration map of 1904

(c) Integration map in the early $20^{\text {th }}$ century

(d) Integration map in the $1950 \mathrm{~s}$

(e) Integration map in the $1990 \mathrm{~s}$ 
Table 2: Changes of synergy over the historical period

\begin{tabular}{|c|c|c|c|c|c|}
\hline & Axial-map (a) & Axial-map (c) & Axial-map (d) & Axial-map (e) & $\begin{array}{l}\text { With second-le vel } \\
\text { sky walks excluded }\end{array}$ \\
\hline
\end{tabular}

When the first reclamation was carried out, "Planned grid" was added to the north of Johnston Road (Fig. 4c). As a result, the integration map shows that the distribution of integration was not significantly changed, with the most integrated lines still locating in Johnston Road. In this sense, it is fair to infer that theoretically, Johnston Road would attract a larger number of pedestrian activities than other streets, subsequently encouraging movement sensitive facilities, including retail shops to settle down. This may help to explain the phenomenon that the tramway, one of the oldest transportation services of Hong Kong, and a certain number of historical retail shops are situated along this street until today.

When substantial reclamation was carried out between 1921 and the 1950s, the "Planned grid" between the present Hennessy Road and Gloucester Road were added to the north. Consequently, the corresponding axial-line map (Fig. 4d) shows that, irrespective of the changes in the scale and density of the axial lines in the newly reclaimed area, the distribution of global integration (Rn) did not shift apparently. The most integrated lines were still located along Johnston Road, suggesting that the new development did not cause obvious changes to the existing spatial structure. However, it is noticeable that a linear core began to appear in the overall layout, with the distribution of integration values demonstrating a core-to-edge pattern. That is, the shape of the core was clearly defined, and the integration value decreased gradually from the core towards its perimeters. In this sense, those lines with good connections to the core showed higher integration values; and the lines along the waterfront were not as segregated as they are today, since they still had good connections with the core, theoretically the most accessible place. With reference to the above analysis, it may be inferred that, the urban development of Wanchai of this stage still followed a similar spatial logic as the original grids rather than imposing a new spatial order on the site. The urban configuration as a whole had good continuity and connectivity, although their surface properties ${ }^{3}$, including street block size and street layouts, were obviously different.

Further reclamation was carried out around the 1980s. This scheme provided a large number of luxury office buildings for the market with the aim to alleviate the land demand in Central. During this development process, a significant change was recorded in its spatial structure, which has been illustrated by the distribution pattern of integration value (Rn) of the axial map (Fig. 4e). First and foremost, the syntactic core appeared sparse and shallowly distributed over the whole area, with the boundaries between the integrated and segregated areas not being clearly defined. Secondly, the most integrated lines shifted to Gloucester Road South, Johnston Road and O'Brien Road, and virtually no identifiable shape of core could be found, implying that the large-scale urban intervention in the northern part of Gloucester Road did not follow similar spatial logic underlying "Planned grid". Instead, a new spatial order was imposed on the site in light of modernist planning principles. Consequently, the urban structure of Wanchai as a whole had poor continuity, with "Sparse grid" located in the north being remote and relatively isolated from all the other parts of the district.

To examine the changes of the relationship between local and global integration (that is synergy) in keeping with the urban development, the synergy of the four axial maps was also investigated (Table-2). As discussed previously, the synergy value can provide an indication of how the constituent parts are fitted into the overall urban system. Theoretically, an urban system with high synergy value is the one where people can obtain good global information of the spatial layout from its local parts, and then 
subsequently can influence the distribution pattern of pedestrian movement. As illustarted, the original layout of Wanchai displayed a comparatively high degree of synergy. As the area developed into the existing pattern, synergy was gradually weakened. Increasingly, the overall urban structure was characterized by a poor 'part and whole' relationship. This finding is consistent with the previous analysis concerning the distribution of global integration $(\mathrm{Rn})$, which has demonstrated that urban development in Wanchai tended to be more and more locally oriented, and inadequate consideration was given to how local parts could be faithful to the spatial logic of the overall layouts in the later periods. From the configurational analysis, it may be inferred that, although the surface fabric of Wanchai seemed continuous in most circumstances; to exemplify, different layouts are all in the form of a gridiron pattern; the connectivity between them in specific period is interrupted. In this regard, as far as pedestrian movement pattern is concerned, it means that people would find it hard to learn about the overall urban structure since they received poor information from the local parts [14]. That is, for the people within such an environment, the overall plan structure is more likely to be a labyrinth so that they cannot orient themselves.

Being inspired by previous studies concerning the high-density multi-level urban environment [15], this study assumes that the poor local and global relationship may be caused by the second-level skywalks inside the area. To examine this assumption, the analysis is conducted with the second-level skywalk system being excluded. Consequently, the synergy value increases considerably (with $\mathrm{R}^{2}=0.3119$ ), implying that the insertion of the skywalk system has weakened the intelligible level of the area. Finally, the area as a whole is complex and illegible by nature. This finding supports Chang's [15] statement that the high-density multi-level urban environment is always unintelligible and illegible for the people moving around.

\section{Conclusion}

In summary, through tracing the evolution and changes of spatial configuration in the Wanchai District by using axial-line maps analysis, a number of findings can be summarized:

(1) In comparison with physical analysis, configurational analysis is proven to be more effective in analyzing the underlying structure of different urban layouts. As a result, the study can arrive at a precise understanding in respect of two questions: how the deep plan structure of the overall urban grids was evolved over a long historical period, and how far urban development in different periods had implications for the functional aspects, such as the distribution of pedestrian movement, theoretically.

(2) The configurational analysis has revealed that, before the 1950s, the urban development of Wanchai more and less followed a similar spatial logic in its layouts, thus a continuous and intelligible spatial configuration could be found at the time. Nevertheless, since the development in the north part of Gloucester Road was added (that is a "Sparse grid"), the overall intelligibility has been weakened, and the spatial configuration of Wanchai appeared discontinuous and relatively fragmented.

(3) The significance of this study lies in its potential implication for future spatial development in other urban areas. To exemplify, one urban issue of Hong Kong is the performance of the waterfront promenade located in the north of Wanchai. Whilst the waterfront promenade is one of the famous tourist attractions, they are in most circumstances visited by group tourists and little frequented by local inhabitants. How to make it part of the local community life is thereby a critical issue faced by planners. Notwithstanding the fact that the Government recently has carried out a series of schemes to revitalize the waterfront in order to provide an attractive place for both tourists and locals, the proposals in most circumstances were focused on the plan layout or landscape design. Little attention was given to the 
configurational connection of the waterfront and other parts of the urban morphology. In light of the results of this study, it is fair to assert that the waterfront promenade is suffering from its remote and inaccessible location. To make it more easily accessible for a variety of users, some measures can be implemented. The direct way is to increase the number of linkages to lead pedestrians from "Planned grid" to "Sparse grid" so as to overcome the barrier effect of Gloucester Road.

\section{Acknowledge ments}

This research was financially supported by National Natural Science Foundation of China (51138004), State Key Laboratory of Subtropical Building Science Research, South China University of Technology (2016ZB17 \& 2013ZC15) and "Guangzhou Ceremony" and Guangzhou History and Culture Research (2015GZY25).

\section{Notes:}

1. The data are from the latest population census carried out by the Census \& Statistics Department of Hong Kong in 2001

2. A 'segment-line' city was used to describe the urban structure of metropolis of Hong Kong (Source: Hong Kong: Alternative Metropolis, Space Design, No. 330, 1992, 42-43).

3. 'Surface property' was originally used by B. Hillier to describe the conventional geometrical properties in comparison with the configurational properties (Source: B. Hillier. The Morphology of Urban Space: The Evolution of Syntactic Approach. Architecture and Behavior 3, no. 3 (1987), pp. 205-216).

\section{Reference}

[1] P. L. Woo, K. M. Hui. Continuity and Change in the Urban Transformation of Old District: A Case of Sham Shui Po, Hong Kong. Projections 10: Designing for Growth \& Changes (2011), pp.101-106.

[2] B. C. K. Fung. Planning for High Density Development of Hong Kong. Planning Department of Hong Kong (2001). http://www.pland.gov.hk/press/speeches/highden_dev.pdf (accessed June 20, 2005).

[3] B. Hillier and J. Hanson. The Social Logic of Space, Cambridge University Press, Cambridge (1984).

[4] B. Hillier. Space is the Machine, A Configurational Theory of Architecture, Cambridge University Press (1996).

[5] B. Hillier. The Hidden Geometry of Deformed Grids - or, Why Space Syntax Works When It Looks as Though It Shouldn't. The 1st International Space Syntax Symposium, London, (1997).

[6] B. Hillier. Centrality as a Process: Accounting for Attraction Inequalities in Deformed Grids, Urban Design International, Vol.4 (3\&4) (1999), pp.107-127.

[7] B. Hillier. Society Seen Through the Prism of Space - Outline of a Theory of Society and Space. The 3rd International Space Syntax Symposium, Atlanta, also published in Urban Design International (2001).

[8] B. Hiller. A Theory of the City as Object - Or, how spatial laws mediate the social construction of urban space. The 4th International Space Syntax Symposium, London (2003). 
[9] A. Kasemsook. Spatial and Functional Differentiation: A Symbiotic and Systematic Relationship. The 4th International Space Syntax Symposium, London (2003).

[10] X.H. Ling. Accessibility of Open Space: A Study of Urban Morphology and its Relation to Open Space Use in the Wanchai District of Hong Kong, Ph.D. Dissertation, The University of Hong Kong. (2008).

[11] J. Peponis. Space, Culture and Urban Design in Late Modernism and After, Ekistics 56, no. 334 (1989), pp. 93-108.

[12] B. Hillier. Specifically Architectural Theory: A Partial Account of the Ascent from Building as Cultural Transmission to Architecture as Theoretical Concretion. The Harvard Architecture Review 9, (1993), pp.8-27.

[13] B. Hillier, A. Penn, J. Hanson, T. Grajewski, and J. Xu. Natural Movement: or, Configuration and Attraction in Urban Pedestrian Movement. University College London, (1993).

[14] Y. O. Kim. Spatial Configuration, Spatial Cognition and Spatial Behavior: The Role of Architectural Intelligibility in Shaping Spatial Experience. Ph.D. Dissertation, University College London, London (1999).

[15] D. Chang. Integrated Multi-level Circulation Systems in Dense Urban Areas: The Effect of Complex Spatial Designs on Multi-level Pedestrian Movement, Ph.D. Dissertation, University College London, London (2000). 